\title{
PARAguay 2008: eSTRUENDOSOS CAMBIOS, SILENCIOSAS PERMANENCIAS
}

Paraguay 2008: Noisy Changes, Silent Conservation

\section{PABLO BRUGNONI}

Universidad Católica de Asunción

\section{RESUMEN}

En 2008, y por primera vez en la historia política de Paraguay, un partido le cedió a otro el control del gobierno por medios pacíficos y democráticos. El ex obispo Fernando Lugo ganó las elecciones apoyado en una alianza heterogénea y volátil, y asumió la presidencia en un contexto de escasa capacidad estatal y sin un marco de gobernabilidad medianamente consolidado.

Palabras clave: elecciones, alternancia, Lugo, gobernabilidad, Ovelar.

\begin{abstract}
In 2008, for the first time in the political history of Paraguay, there was a substitution of political parties on government through peaceful and democratic means. Former bishop Fernando Lugo won elections supported in an heterogeneus alliance, and assumed the presidency in a context of weak capacity state and without a consolidated governance framework.
\end{abstract}

Key words: elections, alternation, Lugo, governance, Ovelar. 
Tomando en préstamo la licencia de Eric Hobsbawm, que trascendió el estricto calendario y llamó siglos cortos y largos a períodos que se corresponden con las centurias, pero con límites definidos según la unidad histórica que encontraba en sus análisis, podemos afirmar que el año político 2008 en Paraguay comienza quince días antes que el almanaque lo anuncie: el 16 de diciembre de 2007, fecha en que se celebraron las elecciones internas del Partido Colorado, y termina el día 23 de noviembre de 2008 cuando el nuevo gobierno completó sus cien primeros días de gestión.

Durante ese lapso ocurrió un hecho que guardará la memoria y registrarán los libros, inédito en toda la historia del país: el 20 de abril de 2008 una coalición electoral de partidos y movimientos sociales, la Alianza Patriótica para el Cambio, encabezada por el ex Obispo Fernando Lugo, desplazó del gobierno nacional por medio de elecciones libres a otro grupo político, nada menos que el Partido Colorado, gobernante durante más de sesenta años ininterrumpidos, tanto en dictadura como en democracia, dueño y señor de los hilos del poder estatal y con una inserción social e identitaria que confunde sus fuentes con las de la propia nacionalidad paraguaya. Nunca antes se había registrado esa alternancia pacífica y democrática en el poder estatal, inaugurándose, por tanto, un nuevo estadio de evolución de la democracia paraguaya.

Este 2008 así definido posibilita una mirada integral, en tanto incluye el desarrollo de los hechos que podemos identificar como causas inmediatas del histórico resultado electoral, y asistimos a los primeros cien días del fenómeno posterior, que sólo vivieron los más ancianos: un gobierno que no es del Partido Colorado.

\section{EL CONTEXTO SOCIAL Y ECONÓMICO}

Así como ocurrió en la mayoría de los países de América Latina, Paraguay ha logrado en los últimos tiempos mantener una tasa de crecimiento económico superior a la de lustros pasados. En 2007 el crecimiento del PIB real fue del 6,8\%, el más alto en los últimos 26 años. Este crecimiento estuvo dado, básicamente, por la producción de soja, dominada por inversionistas de procedencia brasileña. Ello, además de aumentar la dependencia y vulnerabilidad externa, llevó a la constitución de polos de desarrollo locales delimitados a las zonas de frontera, que alimentan los mercados externos y no favorecen a otros sectores de la economía paraguaya.

Cuadro 1: Indicadores de crecimiento (2002-2007)

\begin{tabular}{lrrrrrr}
\hline Indicadores de crecimiento & 2002 & 2003 & 2004 & 2005 & 2006 & 2007 \\
\hline PIB crecimiento (\%) & 0 & 3,8 & 4,1 & 2,9 & 4,3 & 6,4 \\
PIB per cápita, USD de mercado & 1.329 & 1.353 & 1.382 & 1.395 & 1.429 & 2.116 \\
\hline
\end{tabular}

Fuente Banco Central del Paraguay. 
Esto no impidió, sin embargo, que el crecimiento económico se relacione positivamente con un aumento del empleo y los ingresos de los trabajadores. En el siguiente cuadro se muestra que entre 2005 y 2007 la población ocupada aumentó en 97.000 personas y en 64.000 personas la población subocupada. El desempleo abierto, como aparece en el gráfico posterior, bajó del 7,3\% en 2004 al 5,6\% en 2007.

Cuadro 2: Indicadores de empleo (2005-2007)

\begin{tabular}{lccc}
\hline \multirow{2}{*}{ Indicadores de empleo } & EPH 2005 & EPH 2007 & \multirow{2}{*}{ Diferencia } \\
\cline { 2 - 3 } & Total & Total & \\
\hline Población total & 5.837 .253 & 6.054 .976 & 217.723 \\
Población en edad de trabajar & 4.498 .263 & 4.734 .593 & 236.330 \\
Población económicamente activa & 2.779 .810 & 2.877 .530 & 97.720 \\
Población económicamente inactiva & 1.718 .453 & 1.857 .063 & 138.610 \\
Población ocupada & 2.617 .708 & 2.716 .365 & 98.657 \\
Desempleo abierto & 162.102 & 161.165 & -937 \\
Población subocupada & 698.492 & 762.328 & 63.836 \\
Población subocupada visible & 187.029 & 139.840 & -47.189 \\
Población subocupada invisible & 511.463 & 622.488 & 111.025 \\
\hline
\end{tabular}

Fuente: DGEEC. Encuesta Permanente de Hogares.

Gráfico 1: Evolución del desempleo abierto (2004-2007)

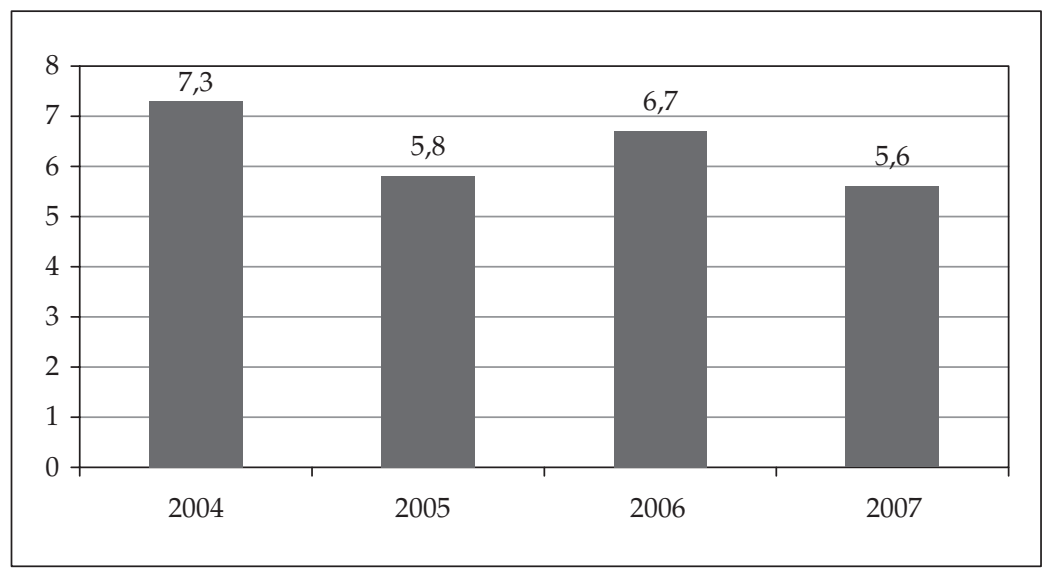

Fuente: DGEEC. Encuesta Permanente de Hogares.

Los ingresos también tuvieron una modificación positiva; el de los pobres extremos aumentó sustancialmente entre 2005 y 2007, tal como se muestra en el siguiente gráfico. En el área rural ese aumentó llegó al 51,7\%. 
Gráfico 2: Variación porcentual de los ingresos nominales de los pobres extremos por área (2005-2007)

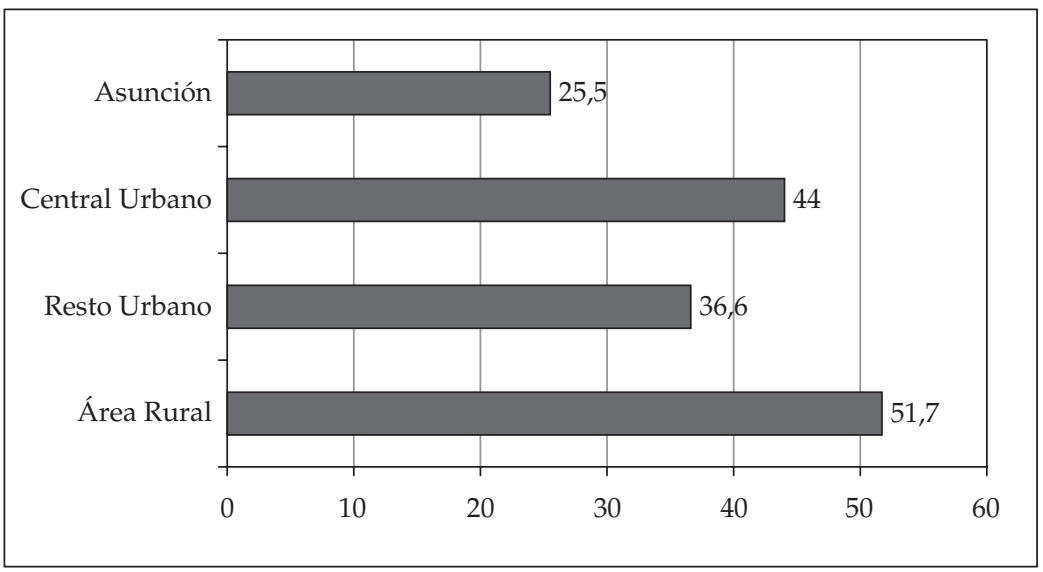

Fuente: DGEEC. Encuesta Permanente de Hogares.

Asimismo, el crecimiento económico afectó positivamente a la pobreza no extrema, que se redujo del $24,6 \%$ en 2002 al 16,3\% en 2007, tanto al nivel urbano ( $43,2 \%$ al 36\%) como rural $(50,5 \%$ al 35$) .{ }^{1}$

Cuadro 3: Indicadores de pobreza (2002-2007)

\begin{tabular}{|c|c|c|c|c|c|}
\hline \multirow{2}{*}{ Área / Estatus de Pobreza } & \multicolumn{5}{|c|}{ Año } \\
\hline & 2002 & 2003 & 2004 & 2005 & 2007 \\
\hline \multicolumn{6}{|l|}{ Urbana } \\
\hline Pobres Extremos & 14,6 & 13,4 & 12,8 & 11,6 & 15,7 \\
\hline Pobres no Extremos & 28,6 & 26,4 & 25,7 & 27,8 & 20,3 \\
\hline Total & 43,2 & 39,8 & 38,4 & 39,4 & 36 \\
\hline \multicolumn{6}{|l|}{ Rural } \\
\hline Pobres Extremos & 31,1 & 28,7 & 22,8 & 20,8 & 24,4 \\
\hline Pobres no Extremos & 19,4 & 14,7 & 17,3 & 15,8 & 10,6 \\
\hline Total & 50,5 & 43,4 & 40,1 & 36,6 & 35 \\
\hline \multicolumn{6}{|l|}{ Total } \\
\hline Pobres Extremos & 21,7 & 20,1 & 17,1 & 15,5 & 19,4 \\
\hline Pobres no Extremos & 24,6 & 21,3 & 22,1 & 22,7 & 16,3 \\
\hline Total & 46,4 & 41,4 & 39,2 & 38,2 & 35,6 \\
\hline
\end{tabular}

Fuente: DGEEC. Encuesta Permanente de Hogares. 
Sin embargo, y tal como resalta en el anterior cuadro, la pobreza extrema tuvo un importante aumento del 30\% entre 2005 y 2007. Este dato significa que 270.000 nuevas personas pasaron a estar en situación de pobreza extrema, a pesar del cambio positivo en las otras variables reseñadas: crecimiento económico y aumento de salarios y de ocupación. Esto es analizado en un reciente informe, ${ }^{2}$ donde se atribuye el resultado a la inflación y especialmente al aumento en el precio de los alimentos, que ha tenido un fuerte impacto a nivel global. Es decir, esas 270.000 personas mantuvieron un nivel de ingresos que quedó por debajo del suficiente para cubrir una canasta cuyo costo aumentó sustancialmente.

El siguiente gráfico muestra la inflación entre 2005 y 2007 discriminada según diversos rubros. Se puede apreciar que si bien el índice general de inflación fue del 19,2\% el índice de inflación específico de los alimentos ascendió al 39,7\%.

Gráfico 3: Inflación acumulada entre 2005 y 2007 según rubros

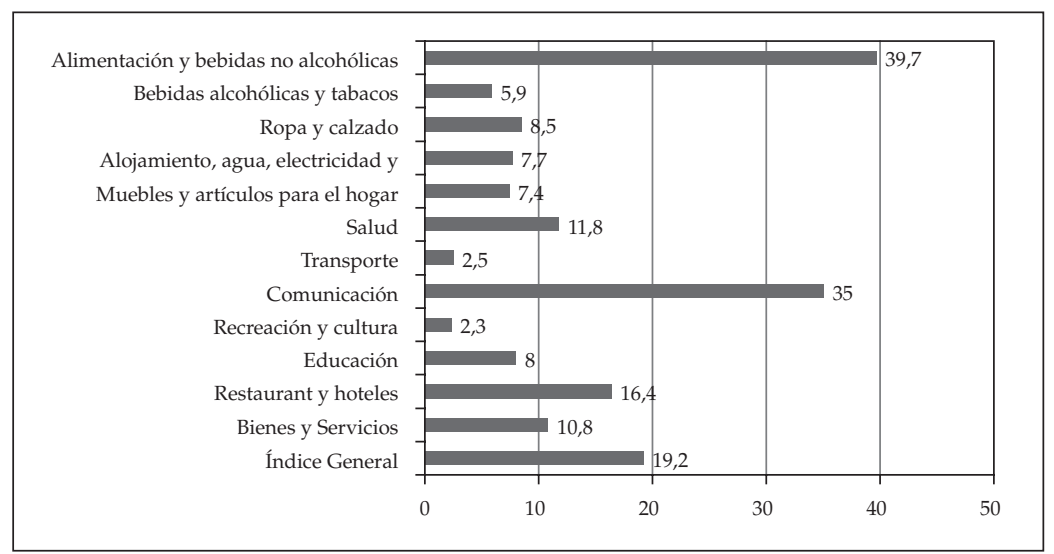

Fuente: Banco Central del Paraguay, extraído de "Impacto del aumento de precios de alimentos y de la crisis financiera global en la pobreza extrema", enero de 2009.

Esta situación económica y social ha sido el contexto en el que se inició el período 2008. Aún no se tienen suficientes datos oficiales sobre la evolución económica y social durante este año. Se confirmó que las exportaciones paraguayas alcanzaron un récord histórico por octavo año consecutivo, con una venta total de productos al exterior por valor de US\$ 4.433 millones. El crecimiento económico se mantuvo alto, estimándose en un 5,8\%, menor en un punto porcentual al del 2007. Esta tasa de crecimiento superó al vegetativo, considerando que la población paraguaya aumenta a un promedio del $2 \%$ anual.

El alto precio de los alimentos permaneció hasta la mitad del año, con un abrupto descenso en el segundo semestre. Según el Banco Central del Paraguay, la tasa de inflación acumulada de alimentos, sin considerar frutas ni verduras, bajó del 14,7\% en

2 "Impacto del aumento de precios de alimentos y de la crisis financiera global en la pobreza extrema". Paper del Programa Conjunto PNUD-UNICEF-UNFPA “Invertir en la Gente”, enero de 2009. 
noviembre de 2007 al 8\% en noviembre de 2008. Sin embargo, esta crisis alimentaria fue sustituida, casi en perfecta continuidad, por la crisis financiera mundial. Efectivamente, en la segunda mitad del 2008 los expertos identificaron indicios de disminución del ritmo de crecimiento económico determinado, en gran parte, por el efecto combinado del aumento del desempleo, la caída de los ingresos reales y la reducción de las remesas. Esta tendencia se reflejó tímidamente en los indicadores del 2008 pero se consolida como el gran desafío en el 2009. En el siguiente gráfico se puede apreciar la diferencia entre las exportaciones estimadas (2008 P) y las efectivamente alcanzadas durante el año (2008). En el informe del BCP, de donde se obtuvo la información, esa brecha es atribuida a la crisis financiera mundial.

Gráfico 4: Ingresos por Exportación de Soja y Carne, Remesas y Binacionales. Efectos de la crisis financiera mundial (en millones de dólares)

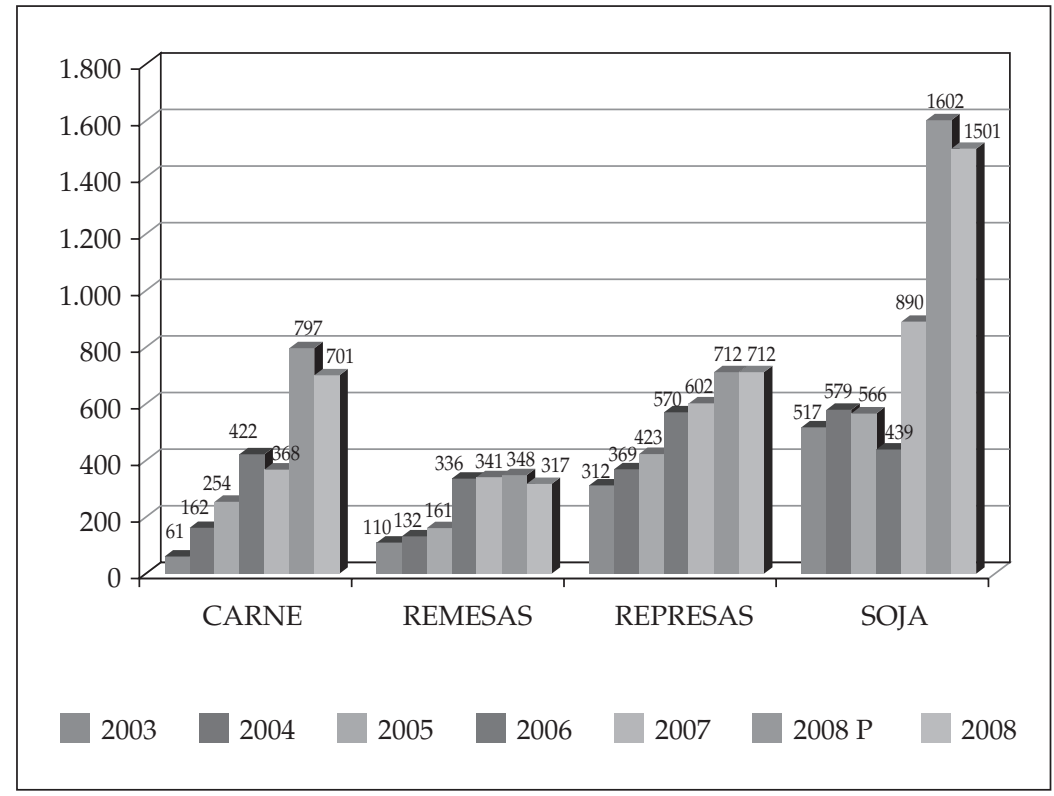

Fuente: Informe Económico Preliminar 2008 del Banco Central del Paraguay.

La tasa de participación laboral (población ocupada o desocupada respecto a la población total en edad de trabajar) en 2008 fue del 61,7\% siendo los porcentajes similares en áreas urbanas y rurales (62\% y 61,5\%, respectivamente). Unas 170.000 personas buscaron activamente empleo durante ese período sin conseguirlo. Esto significa una tasa de desempleo abierto de 5,7\%. En 2007 había llegado al 5,6\%, por lo que se verificó un mínimo aumento del 0,1\%.

De los 2,8 millones de personas ocupadas, aproximadamente 790.000 trabajan menos de 30 horas a la semana, y quieren trabajar más, o trabajan 30 horas semanales o más, pero perciben un ingreso inferior al mínimo legal vigente. Esto equivale a un 26,5\% de subempleo. 
Cuadro 4: Indicadores del mercado laboral en Paraguay. Clasificación de la población

\begin{tabular}{|c|c|c|c|c|c|}
\hline \multirow{6}{*}{$\begin{array}{l}\text { Población } \\
6.163 .913 \\
(100 \%)\end{array}$} & \multirow{5}{*}{$\begin{array}{l}\text { Población en } \\
\text { edad de trabajar } \\
4.830 .009 \\
(78,4 \%)\end{array}$} & \multirow{4}{*}{$\begin{array}{l}\text { Población } \\
\text { económicamente } \\
\text { activa 2.981.126 } \\
(61,7 \%)\end{array}$} & \multirow{2}{*}{$\begin{array}{l}\text { Población } \\
\text { ocupada } 2.810 .506 \\
(94,3 \%)\end{array}$} & \multirow{2}{*}{$\begin{array}{l}\text { Población } \\
\text { subocupada } \\
790.770(26,5 \%)\end{array}$} & $\begin{array}{l}\text { Población } \\
\text { subocupada } \\
\text { visible } 206.987 \\
(6,9 \%) \\
\end{array}$ \\
\hline & & & & & $\begin{array}{l}\text { Población } \\
\text { subocupada } \\
\text { invisible } 583.783 \\
(19,6 \%)\end{array}$ \\
\hline & & & \multirow{2}{*}{$\begin{array}{l}\text { Desempleo } \\
\text { abierto } 170.620 \\
(5,7 \%)\end{array}$} & \multicolumn{2}{|c|}{$\begin{array}{l}\text { Desempleados por } 1^{\text {a }} \text { vez } \\
42.893(25,1 \%)\end{array}$} \\
\hline & & & & \multicolumn{2}{|c|}{$\begin{array}{l}\text { Desempleados por } 2^{\mathrm{a}} \text { vez o más } \\
127.727(74,9 \%)\end{array}$} \\
\hline & & \multicolumn{4}{|c|}{ Población económicamente inactiva $1.848 .883(38,3 \%)$} \\
\hline & oblación mon & 10 años 1.333 .90 & $(21,6 \%)$ & & \\
\hline
\end{tabular}

Fuente: Encuesta Permanente de Hogares. DGEEC.

En suma, el año 2008 se inició en un contexto económico favorable, pero con un alza del precio de los alimentos persistente desde años anteriores que tuvo un impacto muy severo en la extrema pobreza, aumentando sustancialmente su prevalencia. En el curso del año la "crisis alimentaria" disminuyó en correspondencia con la baja de la inflación en ese rubro, pero el país comenzó a sentir el impacto, aunque todavía muy incipiente, de la crisis financiera mundial. ${ }^{3}$ Esta situación social y económica enmarca el año esencialmente político que vivió Paraguay en 2008 y que se inicia, como decíamos, en las elecciones internas.

\section{LAS ELECCIONES INTERNAS}

Todos los partidos políticos, movimientos políticos y coaliciones de partidos tienen el derecho a postular candidatos en las elecciones nacionales, que deben ser seleccionados en votaciones internas abiertas a todos sus afiliados. Las internas se realizan entre 90 y 120 días antes de las elecciones nacionales.

El Partido Liberal Radical Auténtico, el más importante de la oposición, celebró sus elecciones internas el 9 de diciembre de 2007. Una excepcional paridad entre los dos principales precandidatos derivó en una judicialización del proceso y en una fractura estructural que se mantiene hasta hoy. El cargo en juego era el de candidato a vicepresidente, ya que la candidatura a la presidencia había sido asegurada para Fernando Lugo. Esto diluyó la percepción de "suma cero" que suelen tener estas elecciones, y seguramente ayudó a disminuir el nivel de conflicto, que, además de por esa inquietante paridad, fue azuzado por las escandalosas diferencias que se manifestaron entre las mediciones de intención de voto de las empresas encuestadoras en los momentos previos y los 
resultados electorales que efectivamente se dieron en las urnas. Si bien las mediciones daban como ganador al ex gobernador del Departamento de Central, Federico Franco, quien fue finalmente proclamado como candidato a vicepresidente, la ventaja que le atribuían previamente era mucho mayor que las exiguas diferencias que se registraron en las actas del escrutinio.

Fernando Lugo se presentó como precandidato por un partido menor de la alianza opositora, el Partido Demócrata Cristiano. Así consiguió su postulación en la chapa presidencial ese sacerdote conflictivo, formado en la teología de la liberación, ex obispo de la diócesis de San Pedro (región muy pobre y con alta movilización social), que había dado su salto a la carrera electoral liderando una multitudinaria marcha ciudadana que pretendía enfrentarse a la política tradicional desde una reivindicación de la sociedad y con el respaldo simbólico surgido de su condición de sacerdote de la Iglesia Católica, que históricamente ha tenido una función integradora de la sociedad paraguaya. Dada la ausencia de liderazgos en el sector opositor, el éxito de esta convocatoria removió las esperanzas de un grupo amplio y heterogéneo, que tenía como objetivo común desplazar del gobierno al Partido Colorado.

Pero el año inicia, como decíamos, con las elecciones internas del Partido Colorado. El vicepresidente en ejercicio, el joven ingeniero Luis Castiglioni, confiaba en ser el candidato del oficialismo para las elecciones nacionales. Dentro de la invisibilidad institucional de la vicepresidencia, que no tiene un rol político que en la práctica resulte sustantivo, logró proyectar una imagen que contenía la fórmula de triunfo colorada en todas las elecciones democráticas desde la apertura democrática, la de constituirse en un agente del cambio para la permanencia: es decir, conjugar la garantía de conservación de las estructuras con un discurso rebelde y modernizante. Esta duplicidad no tiene como objetivo convencer a grupos diversos con mensajes específicos, sino que es un doble mensaje para los mismos grupos hegemónicos o hegemonizados, que asumen la necesidad de renovar en algunos aspectos y áreas pero con una alta aversión al cambio social. Luis Castiglioni cultivó las relaciones internacionales, especialmente con Estados Unidos, detallaba a la prensa sus reuniones con inversores extranjeros y giras de negocios, se enfrentaba dialécticamente a lo más rancio del partido y proponía su depuración, dentro del marco de un gobierno colorado del que ya formaba parte y que privilegiaría el libre mercado y la modernización estatal.

Sin embargo, su buen perfil pudo menos que la intención de control de Duarte Frutos (resultaba ingenuo pensar que, luego de ganar la presidencia, su vicepresidente le guarde la fidelidad que él pretendía) y porque la Ministra de Educación y Cultura, Blanca Ovelar, una técnica con escasa trayectoria en la política partidaria, responsable del relativamente exitoso proceso de reforma educativa, también mostraba un perfil atractivo. El presidente apostó a ella como la candidata oficial para las elecciones internas. La ministra, por sus características personales y las del contexto político en el momento de su surgimiento público, no dejaba de tener la fórmula del éxito: delfín del presidente, surgida, por tanto, desde el centro del anillo del poder tradicional y con su apoyo, pero mujer y técnica, lejos de esos dinosaurios anquilosados de la vieja política 
y con un discurso más social que Castiglioni, tenía el sello del cambio estampado en la póliza de la permanencia.

La mayoría de los votantes colorados parecía inclinarse, de acuerdo a las encuestas, por Castiglioni, quien lograba una ventaja importante y se proyectaba como el siguiente presidente del Paraguay. El joven político sentía la tibieza del poder. Por su parte, Duarte Frutos sufría con su vicepresidente díscolo que alzaba la apuesta con un discurso que le sonaba insolente y desagradecido, mientras recogía una gran adhesión del electorado colorado. Es importante identificar las emociones, porque la cristalización de estos sentimientos encontrados fue una de las razones principales de la escisión partidaria que facilitó la histórica derrota electoral. El resultado de la interna desencadenó dos corrientes emocionales que colisionaron irreconciliablemente: por un lado, en las tiendas castiglionistas se enquistó el resentimiento y, por otro, en las de Blanca Ovelar se desató la soberbia. Esta línea de conflicto cruzó desde las élites a las bases y marcó, en gran parte, la suerte electoral del Partido Colorado.

El nivel de belicosidad de la campaña se elevó fuera de control. Dada la proverbial confianza colorada (sustentada racionalmente en sus décadas de gobierno sin interrupciones) la competencia asumió características de elección nacional: quien ganara la interna adquiría el pase a la presidencia. La maquinaria de movilización de bienes estatales con fines prebendarios desangró los recursos disponibles y las denuncias y agresiones mutuas socavaron la imagen del partido; el resultado fue muy ajustado y cayó, como un fantasma del oscuro pasado, la desconfianza del fraude electoral.

El resultado electoral definitivo demoró meses, y le dio una ajustada victoria a la candidata Blanca Ovelar. Sin embargo, las consecuencias de ese conflictivo proceso todavía no aparecían claras. El tiempo mostraría que la interna colorada afectó el resultado de las elecciones nacionales en, por lo menos, tres aspectos:

1) Instaló la sensación de fraude electoral. No es posible arriesgar una afirmación definitiva respecto a la real influencia del fraude en los resultados finales. Descartando un robo general y sistémico, queda por ver cuánto influyó en los guarismos finales la microcorrupción. Existen ciertas prácticas, ampliamente denunciadas, de acciones que se realizan en la misma mesa electoral con el objetivo de afectar el resultado; algunos son métodos legales pero rozando o transgrediendo el límite y otros son flagrantemente ilegales, como la compra de votos y cédulas. Luego del acto electoral comienza la fiesta jurídica, cada voto, válido o anulado, es susceptible de luchas y judicializaciones donde también se han denunciado múltiples vicios y corruptelas. Sin embargo, como un indicio de que los resultados finales se correspondieron, más allá de los problemas denunciados, con la expresión ciudadana, podemos señalar que las encuestas a "boca de urna" anunciaron que Blanca Ovelar triunfaba por el estrecho margen que finalmente proclamó el tribunal partidario.

Esta sensación de fraude tuvo tres consecuencias: a) la primera y más importante, atrajo la atención internacional respecto a la posibilidad de fraude en las siguientes elecciones nacionales, que derivó en una masiva y fundamental presencia de observadores, cuando en instancias electorales anteriores se pensaba que era un tema relativamente saneado 
(sobre esto volveremos más adelante); este protagonismo internacional fue un obstáculo insalvable para quienes podrían pretender llevar adelante un operativo fraudulento que impidiera la caída del Partido Colorado, b) menoscabó la imagen de Blanca Ovelar, oscureciéndola en la sombra de la corrupción y la manipulación de los poderes fácticos y, c) cristalizó la fractura del Partido Colorado, exacerbando el resentimiento de una porción importante de su propio electorado, que se sintió estafada. A pesar de los repetidos intentos de sus élites, esta herida no se logró subsanar antes de las nacionales.

2) Debido a la paridad en las internas, cada voto multiplicó su valor en un espiral del que los operadores políticos no pudieron salir a tiempo, y los recursos estatales y privados se desangraron en esta prematura lucha prebendaria. Cada día, los medios de comunicación registraban esa movilización descontrolada y cortoplacista que redujo sustancialmente las posibilidades de disponer de recursos durante la puja al nivel nacional.

3) Por último, con el resultado de la interna terminó la estrategia de "ocultamiento" de Duarte Frutos, quien en una explosión de euforia, la misma tarde de las elecciones, apenas conocidos los primeros resultados del escrutinio, asumió la alocución de la victoria, reclamando para sí los méritos y ubicándolos en una trayectoria de éxito personal. La candidata triunfante Blanca Ovelar, sentada a su lado, miraba con elocuente silencio cómo el presidente tomaba el control públicamente y terminaba así con su cautela pública, que había sido fundamental para asegurar la necesaria imagen de renovación. Esto hizo que la elección nacional comenzara a tornarse, a pesar de los intentos por evitarlo, en un plebiscito sobre la permanencia o no de Nicanor Duarte Frutos en el gobierno, lo que no favorecía sus posibilidades electorales.

\section{EL CAMBIO Y EL ESCEPTICISMO}

En la etapa inmediatamente anterior a las elecciones nacionales del 20 de abril el resultado era difícil de predecir. Más allá de las diferencias significativas entre las empresas encuestadoras, se disponía de dos datos contradictorios: por un lado, la intención de voto favorecía a Fernando Lugo (si bien algunas le daban una mínima ventaja y otras mostraban una diferencia que rozaba los veinte puntos). Por otro, la mayoría de la ciudadanía pensaba que el cargo presidencial sería ganado por Blanca Ovelar, a pesar de las preferencias, lo que no sólo se constataba en las encuestas, sino en el lenguaje cotidiano de todos los actores políticos, del gobierno y la oposición. Esta divergencia entre la intención de voto y la expectativa del resultado era significativa e incorporaba un importante elemento de duda sobre el resultado final. ${ }^{4}$

4 Ya antes de las elecciones internas, el diario Última Hora publicó una encuesta de Equipos Mori en la que se identificaba esta contradicción. Meses después, cuando restaba una semana para la celebración de las elecciones nacionales, el mismo diario presentó una encuesta de COIN en la que se mostraba que la diferencia entre intención de voto y expectativas de triunfo se había reforzado: Lugo aventajaba a Ovelar por 6 puntos en la intención de voto, sin embargo, sólo el 36\% creía que ganaría, y el 41\% le daba más probabilidades a la candidata colorada. Ver "Sólo el 36\% de los encuestados cree que el ex obispo triunfará", diario Última Hora, 14 de abril de 2008, Asunción. 
El escepticismo respecto a las posibilidades de triunfo de Lugo nos remite a un obstáculo que va más allá de la real integridad del proceso electoral, como es la desconfianza ciudadana respecto a la transparencia de las elecciones. Si bien se han logrado avances significativos en el control del fraude durante los años recientes, se mantiene la percepción de que los resultados electorales no responden a lo expresado por los votantes en las urnas. Esto se relaciona menos con la manipulación del proceso que con el desprestigio general de las instituciones del Estado y de la democracia, ${ }^{5}$ que han manifestado un progresivo deterioro en el aprecio ciudadano desde la apertura democrática. La institución encargada de brindar las garantías de transparencia en las elecciones, el Tribunal Superior de Justicia Electoral, tiene una calificación muy negativa, dentro del promedio de desprestigio generalizado de la institucionalidad democrática del Paraguay.

Gráfico 5: Grado de confianza en las instituciones. Aquí se grafica la respuesta: “Nada de confianza..."

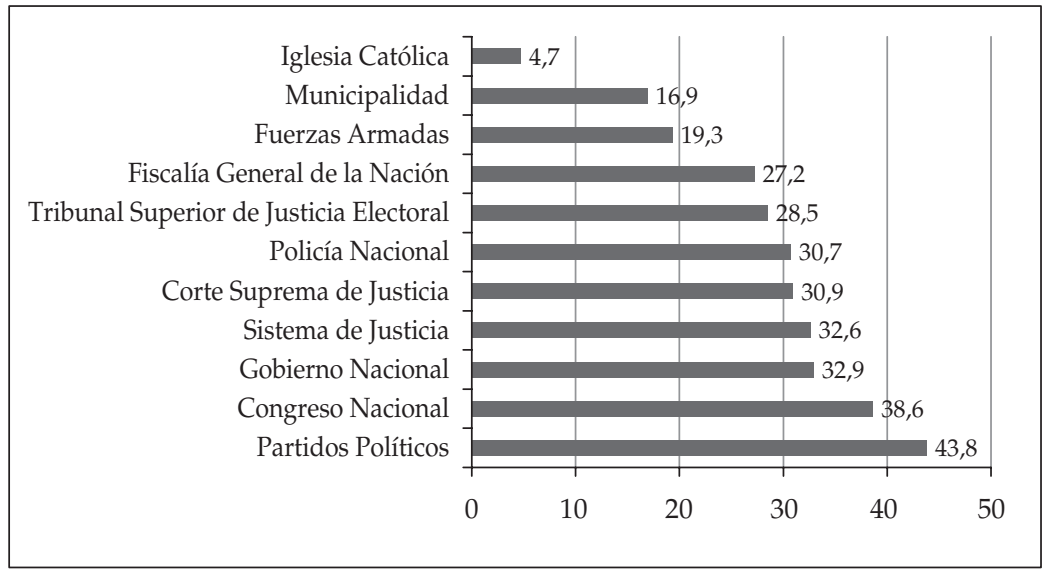

Fuente: Alejandro Vial: "Cultura política y gobernabilidad democrática 2006", CIRD, Asunción, 2006.

Las primeras elecciones nacionales libres de la restaurada democracia, en 1993, que le dieron el triunfo a Wasmosy, fueron calificadas por la prensa nacional e internacional como "libres, pero no justas". La principal fuente de crítica fue el padrón electoral, prácticamente igual al utilizado en tiempos de Stroessner. No hubo un proceso de depuración transparente que brinde un mínimo de confianza. Asimismo, grupos de

5 Son significativos los hallazgos de una investigación comparada: “(En Paraguay) De acuerdo al modelo las personas con ninguna confianza en los poderes públicos y no partidarios del gobierno tienen una probabilidad del $1 \%$ de pensar que las elecciones son limpias. Por otra parte, para las personas con muy alta confianza en los poderes públicos y partidarias del gobierno esa posibilidad es de 78\%". José Molina y Janeth Hernández: “La credibilidad de las elecciones latinoamericanas y sus factores. El efecto de los organismos electorales, el sistema de partidos y las actitudes políticas". Ponencia presentada en el XXI Congreso Internacional de la Asociación de Estudios Latinoamericanos (Latin American Studies Association, LASA), The Palmer House Hilton Hotel, Chicago, Illinois, 24 al 26 de septiembre de 1998. 
observadores neutrales, como NDI, Freedom House y LASA denunciaron la existencia de abusos y fraudes sistemáticos, que incluyeron la falta de garantías en los cuartos de votación, la votación múltiple y la alteración de los padrones para eliminar los nombres de muchos partidarios de la oposición. Así también, se comprobó una utilización masiva de los recursos del Estado. Los empleados públicos fueron obligados a hacer campaña a favor del candidato oficial durante horas regulares de trabajo.

Se hicieron progresivos esfuerzos para garantizar la transparencia en las siguientes elecciones; si bien en 1998 y en 2003 se detectaron los mismos problemas que en 1993, tuvieron una incidencia sustancialmente menor. Por ello, el fraude electoral pasó a ser considerado algo así como un "impuesto" que reduce la fuerza electoral de la oposición; la constatación de irregularidades no llevó a que se asuma el fraude como una barrera infranqueable para la oposición sino como un obstáculo que, si bien impedía la estricta igualdad, dejaba suficiente margen de competencia. En un artículo posterior a las elecciones de 2003, una analista se lamentaba de que, a pesar de su mala gestión, "la ANR (Partido Colorado) ganó en elecciones libres y competitivas otro período gubernamental de cinco años". Posteriormente, entre las variadas razones de ese triunfo citaba: "la tolerancia con que tribunales electorales controlados por la oposición han dejado pasar -una y otra vez- prácticas de corrupción y compra de votos, y oscuros financiamientos de campaña, que benefician sobre todo al partido oficialista" ${ }^{6}$ Es decir, se consideraba que el Partido Colorado corría con una ventaja "ilegítima", pero eso no cuestionaba el marco "libre y competitivo" de la contienda.

Para explicar la falta de confianza en el triunfo opositor, esta desconfianza en la transparencia de las elecciones se debe entrelazar con un problema estructural de la democracia paraguaya: el hecho de que hasta las últimas elecciones no se hubiera dado en toda la historia política del país una sustitución partidaria democrática en la dirección del Estado no era una ausencia más, por el contrario, la falta de alternancia permeó la lógica de funcionamiento del sistema político, ingresando en el inconsciente de la ciudadanía y de las élites políticas como un espíritu negador, invisible y sutil, de que en el futuro cercano pueda existir un cambio democrático de partidos en el gobierno.

Esta carencia ha afectado la dinámica entera del sistema político, desde el votante a los políticos profesionales. La posibilidad de una transición a un gobierno de otro partido era sentida, en primer lugar, como una fractura institucional, más que como un cambio natural y propio del régimen político. En segundo lugar, y en gran parte determinado por lo anterior, esa alternancia aparecía como un fenómeno inverosímil, como una posibilidad exageradamente improbable. Por supuesto, esto no se manifestaba explícitamente, ni siquiera era siempre consciente; era un fantasma que deambulaba en la inconsciencia y las palabras no dichas y que aparecía detrás de ese descreimiento en un cambio que implicara un desplazamiento del Partido Colorado. 
Al diluirse en un horizonte confuso la posibilidad de alternar partidos en el gobierno la lógica de funcionamiento real del sistema había pasado a ser un híbrido entre la democrática y la autoritaria. Porque esta percepción colectiva tiene múltiples impactos, siendo el más importante la limitación del valor que los ciudadanos le otorgan al voto. Evidentemente, si no se asume la posibilidad de un cambio, qué importancia puede tener elegir a los próximos gobernantes. Quien está en desacuerdo con el gobierno, es un votante desahuciado, si es que vota; paralelamente, quien está de acuerdo toma como impertinentes a las voces críticas, en tanto cuestionan un orden naturalizado. Ambos extremos representan perfiles que fácilmente pueden deslizar, y de hecho han deslizado, hacia actitudes autoritarias.

Antes de continuar con el análisis de las elecciones, es necesario responder a una interrogante para contextualizar el proceso de consolidación democrática en Paraguay: Según lo dicho hasta aquí: ¿Existía realmente la posibilidad de alternancia antes de 2008? Porque de no ser así, debemos ubicar estas elecciones, ocurrida la caída de Stroessner hace ya dos décadas, como la real transición en el país. Podemos responder que si bien no hubo un cambio de partidos en el gobierno y predominó cierto escepticismo respecto a la transparencia de las elecciones y la posibilidad de triunfo de la oposición, es posible afirmar que la contingencia de una alternancia sí existía.

En primer lugar, y como vimos, en las tiendas opositoras predominaba la consciencia de que actuaban en desventaja frente a la estructura estatal, pero como una disminución, no una imposibilidad. En segundo lugar, y definitorio, en las elecciones nacionales del 13 de agosto de 2000 (convocadas sólo para la vicepresidencia, como consecuencia del magnicidio del que resultó víctima el entonces vicepresidente, Luis María Argaña y de la posterior renuncia del Presidente Raúl Cubas Grau) triunfó el candidato opositor.

Ocurridos el crimen del vicepresidente y la renuncia del presidente, y dado que la Constitución Nacional no prevé la doble acefalía, la Corte Suprema de Justicia resolvió que quien en ese momento ejercía como Presidente, Luis Ángel González Macchi, debía completar el período constitucional y que el Tribunal Superior de Justicia Electoral debía convocar a elecciones, únicamente para el cargo de Vicepresidente de la República.

Luego de una intensa campaña, ganó el candidato del Partido Liberal Radical Auténtico sobre el del Partido Colorado por menos del 1\%. Esto significó una importante derrota electoral al nivel nacional del Partido Colorado. Si bien no tuvieron el impacto que alcanzan las presidenciales debemos considerar que la participación alcanzó al 64\% del electorado a nivel nacional y que la justa tenía un alto valor simbólico, dada la legitimidad que le otorgaría, en un momento de alta inestabilidad política, a quien obtuviera la preferencia ciudadana. En esas circunstancias decisivas, un candidato liberal triunfó sobre el oficialista. Esto nos sugiere que antes de que ocurra efectivamente en 2008, la posibilidad de alternancia ya existía, más allá de la incredulidad opositora y las argucias oficialistas. 


\section{LA CAMPAÑA ELECTORAL}

Para entender lo que ocurrió durante la campaña electoral, debemos recordar que en Paraguay las adhesiones políticas se definen especialmente por las identidades, por los elementos subjetivos que despiertan o inhiben los partidos y candidatos, antes que por el contenido programático de las propuestas. Asimismo, esas identidades cruzan la estructura social. Si tomamos en cuenta la lengua hablada como un indicador relativamente aproximado (el único con información reciente disponible) del estrato socioeconómico de los votantes, considerando el bilingüismo y el uso exclusivo del español como indicador de las clases urbanas y más acomodadas, vemos que el PLRA recoge adhesiones en las clases más bajas, siguiéndole el partido UNACE y la ANR. El voto independiente se relaciona con los estratos socioeconómicos más altos.

A modo de ejercicio, si sumamos los votos independientes y los correspondientes a los afiliados al PLRA, y comparamos con los demás partidos, vemos que existe una tendencia a la homogenización de la estructura socioeconómica de los diferentes grupos que presentaron candidaturas. Esto se ajusta al imaginario social heterogéneo y policlasista de los partidos políticos paraguayos.

Gráfico 6: Afiliación declarada por lengua hablada

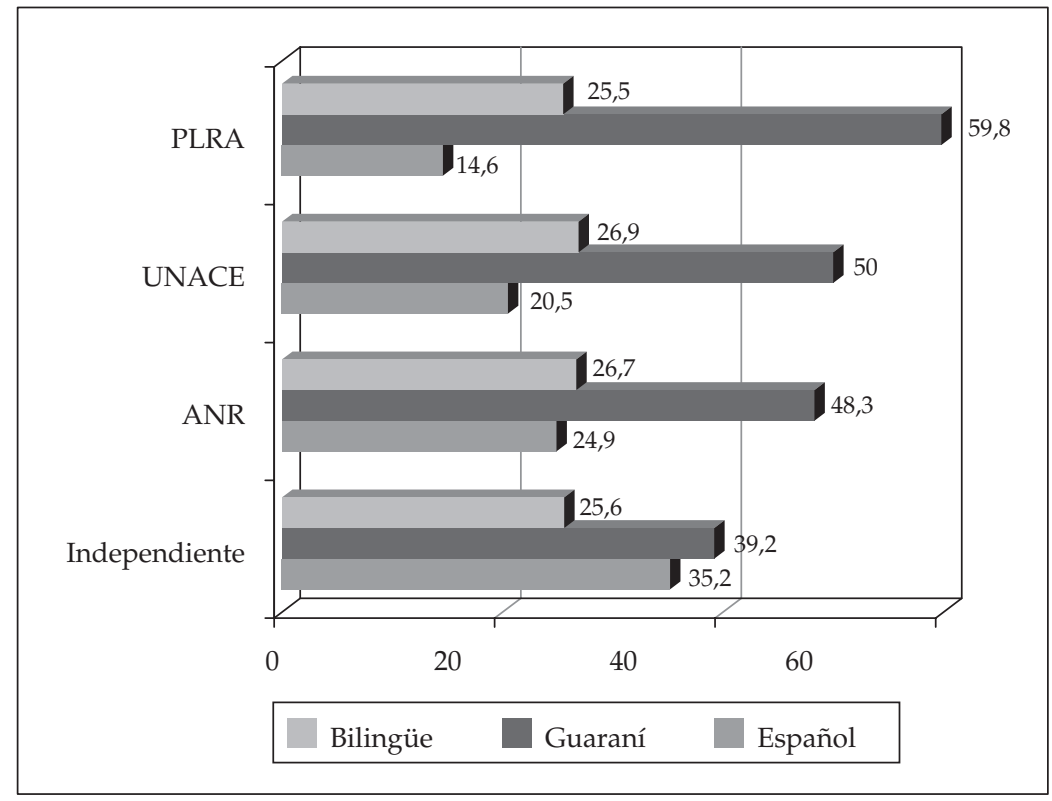

Fuente: “Encuesta sobre indicadores de gobernabilidad” PNUD Paraguay, 2009.7

7 “Encuesta sobre indicadores de gobernabilidad" PNUD Paraguay, 2009. Disponible en: http://www.undp. org.py/images_not/indicadores.zip 
La estrategia electoral del Partido Colorado pareció regirse por el siguiente razonamiento: a) El primer axioma señalaba que los votantes tradicionalmente identificados con el partido alcanzaban para ganar las elecciones. ${ }^{8}$ En la interna colorada participaron 814.046 ciudadanos, los que si se inclinaban por el partido en las nacionales, asegurarían el triunfo.

Esto era así porque, desde el otro lado, la oposición aparecía debilitada. Fernando Lugo, con su Alianza Patriótica para el Cambio, contaba solamente con los votos "cautivos" que le proveía el Partido Liberal Radical Auténtico. Poco tiempo atrás, en una jugada muy riesgosa, Duarte Frutos había facilitado la liberación del ex General Lino César Oviedo, encarcelado por el intento de Golpe Militar de 1996 e investigado por el asesinato del vicepresidente José María Argaña. Esto respondía a un acuerdo por el cual el partido del ex General, la Unión Nacional de Ciudadanos Éticos (UNACE), que se había escindido del Partido Colorado y mantenía un voto duro de la quinta parte del electorado, deserte de la Alianza Patriótica para el Cambio. Efectivamente, apenas sale de prisión proclama su postulación independiente. Esa deserción implicó un descenso inmediato de la intención de voto hacia Lugo que se correspondió al caudal electoral de Oviedo.

Asimismo, el Partido Patria Querida (PPQ), un partido de centroderecha que había ocupado el "tercer espacio" distinto al colorado y liberal en las elecciones de 2003 alcanzando el 15\% de los votos, decidió no integrarse a la alianza opositora. Si bien su fuerza electoral fue menor en 2008, la ausencia restó fuerza a la idea de un frente heterogéneo y modernizante.

Esta fragmentación, consecuencia de la histórica debilidad del sistema político paraguayo para establecer acuerdos y de los intentos deliberados del gobierno para promoverla, mostraba un escenario alentador a los intereses colorados, que debían encargarse de convencer a quienes ya sentían cierta afinidad partidaria.

b) El segundo axioma decía que para lograr esos votos "afines" la campaña debía apelar a los símbolos partidarios, revitalizando la identidad colorada para incluir también a los menos comprometidos, considerando la necesidad de recomponer la fractura que había dejado la elección interna. En esa inteligencia, los actos se volvieron monocromáticos, inundados de banderas y pañuelos colorados, con la presencia cada vez más frecuente de los políticos tradicionales, con demostraciones de poder y autosuficiencia. Esta estrategia, sin embargo, no tuvo en cuenta algunos aspectos que, finalmente, perjudicaron su éxito:

1) Blanca Ovelar tenía muy poca experiencia política. No disponía de los recursos oratorios para insuflar de entusiasmo a las masas y mostrar una imagen de poder, como esperaban quienes dirigían la campaña. Se veía incómoda y parecía forzada a decir lo que no sentía. Sus ventajas comparativas como técnica, mujer y renovadora quedaron ocultas detrás del intento infructuoso de mostrar poder e identidad colorada. 
2) Debido a lo anterior, y firmes en su propósito de ganar a "puro coloradismo", comenzaron a aparecer los políticos tradicionales, para cubrir lo que a la candidata le faltaba. Orgullosos de su oratoria y aura de poder, ocuparon los espacios y encendieron la más cruda tradición. Pero estos políticos se identificaban con un estilo de gestión que los ciudadanos, incluida una buena parte de los colorados, ya no compartín. Existe una invisible línea que separa la vocación de poder, que muchos admiran y respetan, especialmente cuando le confiarán a su portador el gobierno durante el siguiente lustro, de la imagen de arbitrariedad y prepotencia. Cuando la demostración de poder, tradicional del Partido Colorado, ya no se realizó desde la seguridad magnánima, sino desde la fractura y la inseguridad, la sensación mutó, para muchos, en soberbia injustificada.

3) El énfasis en los valores colorados y el olvido de las virtudes renovadoras de la candidata dejó al desnudo un discurso continuista que no brindaba sensaciones de cambio. La históricamente exitosa estrategia del cambio y la continuidad quedó amputada, atada totalmente a la continuidad y expuesta a las críticas al gobierno de Duarte Frutos.

Desde las tiendas contrarias, la estrategia electoral de Lugo estuvo marcada por la cautela, por la previsión de no enfrentar la identidad colorada, para convertirse en sólo un sobrio crítico de los líderes que mantenían el control del Partido Colorado "coyunturalmente", así como por la actitud conciliadora y poco comprometida respecto a los temas conflictivos. Esa pasividad eludía las definiciones claras, manteniendo las propuestas en el limbo de una idea difusa de "cambio" que no parecía tener enemigos ni problemas. Evitó los conflictos y los escándalos e insinuó más de lo que dijo.

Podemos atribuir esta estrategia a tres razones: a) al cálculo político que señalaba la ventaja de sumar adhesiones desde el carisma personal, dejando que cada elector le impute las cualidades que consideraba importantes, b) a las características personales de Lugo, impresas por su formación sacerdotal, que nos remontan a la confianza casi mística en un largo plazo que es relativamente indiferente a las decisiones y acciones del presente y, c) a la heterogeneidad de la alianza electoral que lo apoyaba, que amenazaba con fracturarse si se asumían posturas claras respecto a temas difíciles de consensuar.

Durante los debates televisivos quedó ilustrada la preocupación de Lugo por no comprometer ningún posible voto colorado. Esto a pesar de que muchos de sus adherentes quedaban con los nervios rotos, frustrados por la ausencia de críticas a un gobierno y un partido que entendían como el culpable de todos los males actuales y pasados. La ausencia de pronunciamientos ideológicos claros y las características del heterogéneo grupo de apoyo que incluía a líderes liberales, de centro, de centroizquierda y de izquierda radical, hacían de la candidatura de Lugo una incógnita, hacia dentro y hacia fuera, que no se terminará de definir aún después de haber alcanzado el gobierno nacional.

El otro candidato importante fue Lino César Oviedo. En prisión desde junio de 2004, el Presidente Duarte Frutos facilitó su liberación en la misma fase electoral para desactivar la alianza que había establecido con Lugo. La primera presentación electoral de UNACE, en 2003, luego de escindirse del Partido Colorado, había alcanzado el 13\% de los votos. Cifra importante tomando en cuenta que su líder se encontraba en prisión. Esas elecciones habían mostrado la primera fractura electoral importante del Partido Colorado. Con 
un discurso paternalista y ético, demostrando la fuerte impronta de su origen militar, el retorno de Oviedo le dio mayor pluralidad a la campaña electoral. No se guardó críticas ni a Fernando Lugo ni a Blanca Ovelar, pero con diferentes efectos: respecto al ex Obispo existía poco espacio de competencia, sin embargo, frente a la candidata colorada tenía un potencial electorado en común. Asimismo, a nivel de imagen pública mostraba muchas de las características que ella y su equipo pretendían, iluminando sus debilidades. Estas dos razones, aunadas al origen colorado del candidato, permiten suponer que la campaña de Oviedo restó sustancialmente más votos a la candidata colorada que a Fernando Lugo.

\section{EL 20 DE ABRIL}

El día de las elecciones hubo un amplio operativo de observación nacional e internacional que cubrió casi todo el país. ${ }^{9}$ En un día tranquilo, sin mayores incidentes, votó el 65,48\% de los ciudadanos habilitados. La principal noticia en las horas previas al cierre de las urnas fue la declaración de Luis Castiglioni, quien había perdido las elecciones internas del Partido Colorado, reiterando con contundencia su oposición a la candidatura de Blanca Ovelar. Esto echó por tierra las especulaciones que se habían lanzado desde tiendas coloradas durante los días previos insinuando la cristalización de un acuerdo, una reconciliación interna, que habría terminado en el esperado "abrazo republicano" (expresión popular que alude a la actitud histórica de los colorados de olvidar sus diferencias internas al momento de competir con otros partidos). Las declaraciones de Castiglioni fueron un duro golpe para el partido que, promediando la jornada electoral, sabía fuertemente comprometida su suerte electoral.

Las horas siguieron en calma, pero tensas. El mudo rumor del cambio comenzó a ocupar los espacios llenos de incertidumbre. ¿Qué reacción se podía esperar del Partido Colorado? Nada de lo que profetizaban los apocalípticos ocurrió. El "orden natural" se quebró sin la menor resistencia. Con la información de las encuestas a boca de urna, que marcaban una diferencia de 10 puntos porcentuales, esa misma noche todos los candidatos aceptaron el triunfo de Lugo, que se proclamó como el siguiente presidente de los paraguayos. La democracia paraguaya resistió una prueba de fuego y esa noche, más allá de la alegría o la tristeza de unos y otros, el sueño fue conciliado en una atmósfera de sorpresa.

El Partido Liberal Radical Auténtico hizo una excelente votación para el Legislativo, alcanzando en el parlamento guarismos similares a los del Partido Colorado. UNACE se consolidó como un actor fundamental de la gobernabilidad, especialmente por el apoyo obtenido por Lino Oviedo como candidato a presidente, que obtuvo la quinta parte del electorado, a pesar del voto útil. Es ilustrativa de la fractura del Partido Colorado la diferencia entre los votos alcanzados por la fórmula presidencial (30,63\%) y los recibidos por los candidatos a gobernadores $(37,42 \%)$. Esto sugiere que algunos colorados disidentes

9 La misión de la OEA estuvo liderada por la ex Canciller colombiana María Emma Mejía y la misión de IFES por el ex Presidente colombiano Andrés Pastrana. Ambos tuvieron alta exposición pública. 
decidieron apoyar a su partido solamente para los cargos locales, inclinándose por otro partido, probablemente por la candidatura de Lino Oviedo, en la presidencial. El Partido Colorado recibió 283.000 votos menos que los obtenidos en su interna. ${ }^{10}$

Cuadro 5: Resultados de la votación para Presidente y Vicepresidente

\begin{tabular}{|c|c|c|c|}
\hline Sigla & Partido & Votos & $\%$ \\
\hline ANR & Asociación Nacional Republicana & 573.995 & 30,63 \\
\hline PHP & Partido Humanista Paraguayo & 6.744 & 0,36 \\
\hline APC & Alianza Patriótica para el Cambio & 766.502 & 40,90 \\
\hline UNACE & Unión Nacional de Ciudadanos Éticos & 411.034 & 21,93 \\
\hline PPQ & Partido Patria Querida & 44.060 & 2,35 \\
\hline PT & Partido de los Trabajadores & 3.080 & 0,13 \\
\hline MTP & Movimiento Teta Pyahu & 3.080 & 0,16 \\
\hline \multicolumn{2}{|c|}{ Votos en Blanco } & 38.485 & 2,05 \\
\hline \multicolumn{2}{|c|}{ Votos Nulos } & 27.818 & 1,48 \\
\hline
\end{tabular}

Fuente: Tribunal Superior de Justicia Electoral. “Elecciones 2008. Resultados Finales”.

Gráfico 7: Gráfico Resultados de la votación para Presidente y Vicepresidente

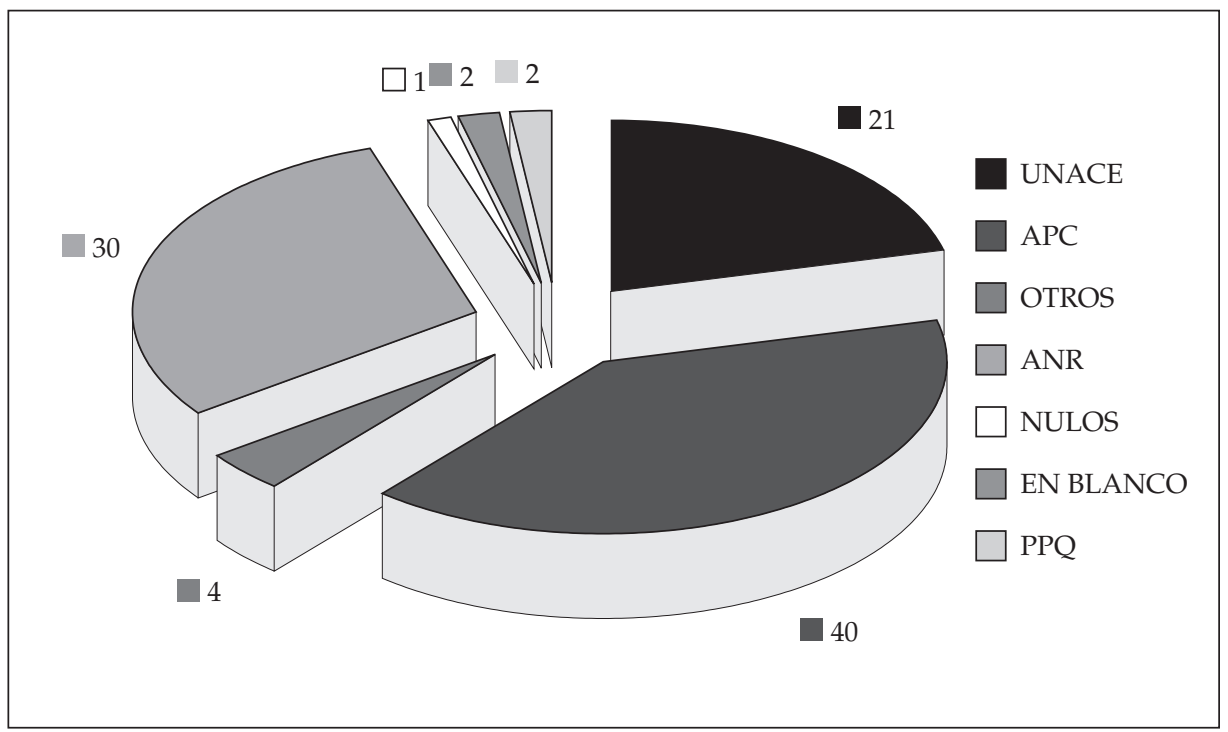

Fuente: Tribunal Superior de Justicia Electoral. “Elecciones 2008. Resultados Finales. 2008. 
Cuadro 6: Resultados de la votación para Senadores

\begin{tabular}{llrr}
\hline Sigla & \multicolumn{1}{c}{ Partido } & \multicolumn{1}{c}{ Votos } & \multicolumn{1}{c}{$\%$} \\
\hline ANR & Asociación Nacional Republicana & 509.907 & 27,23 \\
PLRA & Partido Liberal Radical Auténtico & 507.413 & 27,10 \\
PPS & Partido País Solidario & 60.947 & 3,25 \\
UNACE & Unión Nacional de Ciudadanos Éticos & 336.763 & 17,98 \\
PPQ & Partido Patria Querida & 151.991 & 8,12 \\
PEN & Partido Encuentro Nacional & 20.843 & 1,11 \\
PMAS & Partido Movimiento al Socialismo & 10.564 & 0,56 \\
PUP & Partido de la Unidad Popular & 7.510 & 0,40 \\
MRCN & Movimiento Resistencia Ciudadana Nacional & 9.864 & 0,53 \\
MTP & Movimiento Teta Pyahu & 8.030 & 0,43 \\
MPT & Movimiento Popular Tekojoja & 52.247 & 2,79 \\
PDP & Partido Democrático Progresista & 38.402 & 2,05 \\
Otros & & 39.822 & 2,13 \\
Votos en Blanco & & 73.135 & 3,91 \\
Votos Nulos & & 45.122 & 2,41 \\
\hline
\end{tabular}

Fuente: Tribunal Superior de Justicia Electoral. “Elecciones 2008. Resultados Finales".

Gráfico 8 Resultados de la votación para Senadores

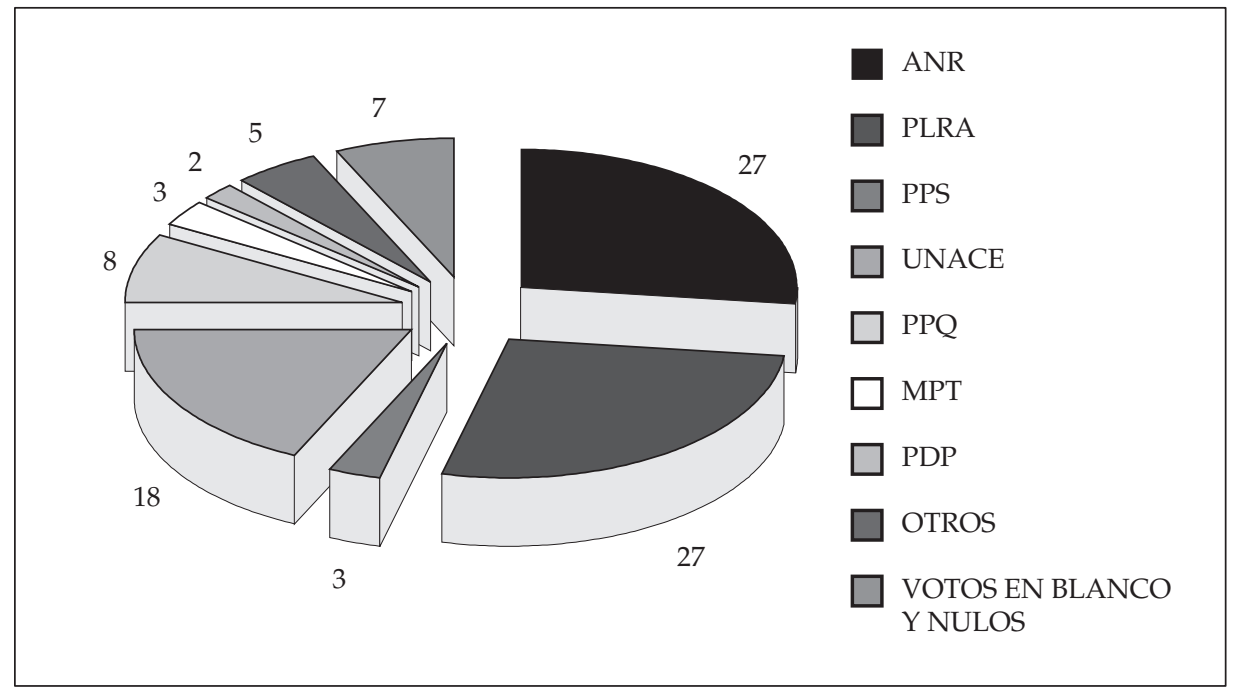

Fuente: Tribunal Superior de Justicia Electoral. "Elecciones 2008. Resultados Finales". 
Cuadro 7: Resultados de la votación para Gobernadores

\begin{tabular}{llrr}
\hline Sigla & \multicolumn{1}{c}{ Partido } & \multicolumn{1}{c}{ Votos } & \multicolumn{1}{c}{$\%$} \\
\hline ANR & Asociación Nacional Republicana & 603.823 & 37,42 \\
PLRA & Partido Liberal Radical Auténtico & 562.464 & 34,86 \\
APC & Alianza Patriótica para el Cambio & 8.837 & 0,55 \\
UNACE & Unión Nacional de Ciudadanos Éticos & 251.410 & 15,58 \\
PPQ & Partido Patria Querida & 25.677 & 1,59 \\
PEN & Partido Encuentro Nacional & 4.664 & 0,29 \\
ERES & Movimiento Esperanza de Renovación Social & 7.739 & 0,48 \\
ADB & Alianza Departamental Boquerón & 6.533 & 0,40 \\
PUP & Partido de la Unidad Popular & 4.685 & 0,29 \\
MPT & Movimiento Popular Tekojoja & 34.746 & 2,15 \\
Otros & & 27.337 & 1,69 \\
Nulos & & 30.188 & 1,87 \\
En blanco & & 45.576 & 2,82 \\
\hline
\end{tabular}

Fuente: Tribunal Superior de Justicia Electoral. "Elecciones 2008. Resultados Finales".

Gráfico 9: Resultados de la votación para Gobernadores

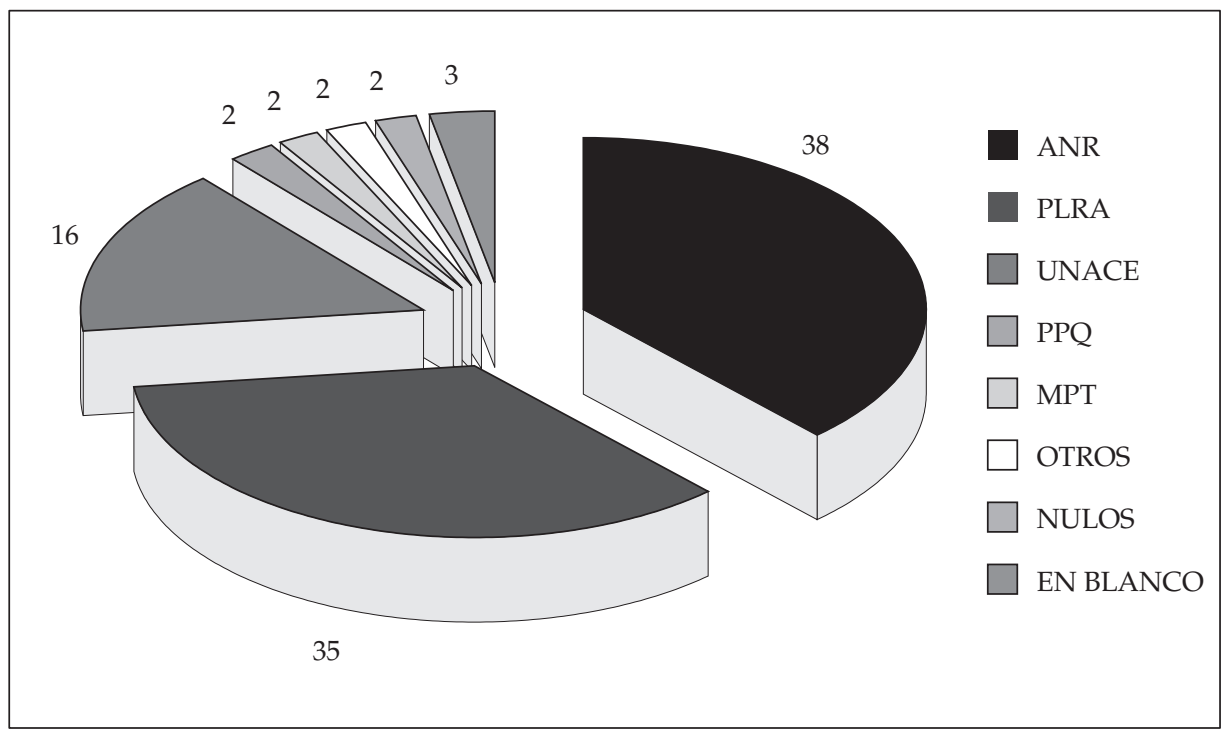

Fuente: Tribunal Superior de Justicia Electoral. "Elecciones 2008. Resultados Finales".

\section{LA GOBERNABILIDAD DE LOS CIEN PRIMEROS DÍAS}

La promesa de cambio se vio sometida desde el primer día al desafío de construir una mínima capacidad de gestión pública que aún hoy no ha logrado. El Estado paraguayo 
tiene una crónica dificultad para desarrollar su estatalidad, es decir, para disponer de los recursos burocráticos y simbólicos necesarios para ordenar jurídicamente la sociedad y orientarla hacia un proceso de desarrollo social y económico. Esta incapacidad ha estado presente cuando el gobernante de turno disponía de cierta ascendencia sobre un funcionariado público que pertenecía a su mismo partido y que le debía el salario. Cuando, como ahora, la mayoría de los funcionarios son ajenos y recelosos, en casos extremos dispuestos a la conspiración y el sabotaje, esa debilidad se exacerba.

A modo de ejemplo, los ingresos que recibe el Estado paraguayo son limitados porque el crecimiento económico también lo es pero, especialmente, por la baja presión tributaria. Según datos del Ministerio de Hacienda, el ingreso fiscal del Estado en los años 90 representó, en promedio, el 10,5\% del PIB. Entre 2000 y 2005 ese promedio ascendió al 10,9\%. Si tomamos en cuenta que en los países vecinos, Brasil y Argentina, la presión tributaria es aproximadamente del 25\% tenemos un significativo indicador de la debilidad del Estado para exigir impuestos y, como consecuencia, para disponer de recursos financieros. Asimismo, resalta que no existe ningún impuesto a la renta personal y que el IVA representa una tercera parte de esa recaudación total. Por tanto, esa escasa capacidad lleva a presionar más sobre quienes menos tienen, derivando en un sistema fiscal insuficiente y fuertemente regresivo.

Asimismo, la gobernabilidad, la habilidad para articular grupos sociales y políticos en pos de objetivos comunes, está limitada por un espacio público fragmentado, donde la confianza mutua, la asociatividad y la cooperación se recluyen en pequeños agregados como la familia o la vecindad. Así se señalaba en un informe sobre la cultura política paraguaya: "En el país siempre ha predominado la comunidad y la 'tribu' por sobre las agregaciones mayores. Las identidades más fuertes son de territorios de pequeño formato, donde ejerce su dominio 'la tribu', la localidad, los vecinos. El gobierno municipal se valora porque es el territorio donde está mi tribu, que es lo que verdaderamente me interesa. Entonces, en un sentido muy profundo, la forma de participación histórica del paraguayo en sus comunidades es totalmente sectorial y corporativa al interés de su grupo local; de los habitantes del pueblo vecino, que son 'los otros' ya se desconfía". ${ }^{11}$

Esta matriz cultural inhibe los acuerdos sociales y políticos y deja a Lugo con pocas posibilidades de armar su esquema de gobernabilidad. Durante sus primeros cien días de gobierno el presidente aún no definió "la cancha" en la que se jugará la gobernabilidad, es decir, el ámbito en el que buscará acuerdos y apoyos. Osciló entre dos escenarios: por un lado, la sociedad civil, o sea, los grupos sociales que podrían salir a la calle a defender su programa y, por otro, el político parlamentario, el de los partidos y las fracciones que votarán a su favor en la legislatura.

Sin embargo, en ambos escenarios los acuerdos fueron escasos y siguen siendo improbables. Los grupos sociales son débiles, están fragmentados y muchos fueron cooptados por el sistema prebendario de gobiernos anteriores, que los llevó a perder

11 “Cultura política y prácticas de gobernabilidad democrática. La ciudadanía en su encrucijada”. USAID, CIRD, Asunción, noviembre de 2002. 
significativamente la legitimidad pública. Su capacidad movilizadora es limitada, y en todo caso ocasional, sin que se disponga de una fuerza militante estable suficiente para convertirse en una herramienta de apoyo al gobierno. El "marzo paraguayo", como se calificó a la reacción popular frente al magnicidio del Vicepresidente José María Argaña en 1999 y que impidió una fuerte amenaza de retroceso al autoritarismo, fue una gesta espontánea y desorganizada, que no logró perdurar en aptitudes participativas. La ilusión del despertar social se frustró en pocos años. Quizás porque facilitó el ascenso a la Presidencia de la República a un político con poca experiencia, Luis González Macchi, que decepcionó a propios y ajenos recibiendo la peor calificación ciudadana entre los gobiernos democráticos. Esto convirtió a esa promisoria gesta en una estación más en la vía de desengaños que siguió a las décadas de violenta represión durante la dictadura de Stroessner, años devastadores para una sociedad civil que aún necesita tiempo para recomponerse, articularse y movilizarse como actor relevante dentro de las reglas de juego democráticas.

A nivel parlamentario tiene la espada de Damocles del juicio político, que le daría el poder a su Vicepresidente Federico Franco, con quien no mantiene una buena relación. El vicepresidente, apoyado en el argumento de que los votos liberales fueron los que realmente permitieron el triunfo de la oposición, asumió en público y en privado en el país y fuera de él, un inquietante rol protagónico apenas se conoció el resultado electoral. Frente a un conflicto menor en el campo, el Partido Liberal Radical Auténtico lanzó una declaración pública enfática sobre su respeto irrestricto a la propiedad privada, en lo que se consideró un reto a la propuesta de reforma agraria integral, uno de los principales ejes del programa de gobierno de la Alianza Patriótica para el Cambio y, especialmente, de Fernando Lugo. Estas manifestaciones adquieren una llamativa importancia si consideramos esa posibilidad de juicio político. Tal como ha ocurrido en los últimos períodos, cuando el vicepresidente no es del mismo grupo político que el presidente, se proyecta y agiganta la amenaza de que las desavenencias políticas faciliten institucionalmente el cambio presidencial, por lo que se transforma en un potencial conspirador. $\mathrm{Si}$, considerando este contexto, aún antes de iniciar el gobierno el vicepresidente se pronuncia en contra de una línea fundamental y especialmente conflictiva del programa, la que implicará quizás mayores costos en su implementación, y a la vez reivindica la legitimidad de ser el partido más votado, ese riesgo parece excesivo.

Frente a ello, Lugo cambió totalmente la distribución de poder dentro del Partido Liberal, brindándole jugosas ofertas a los grupos que no forman parte de la fracción del vicepresidente. La dirección de la represa de Itaipú, la mayor fuente de recursos prebendarios del Estado paraguayo, se la ofreció a Carlos Mateo Balmelli, principal opositor de Franco en las internas. Asimismo, le dio importantes y electoralmente jugosos ministerios a otros líderes liberales, quebrando la estructura del partido y dejando aislado al vicepresidente y su grupo. El criterio de asignación de los puestos correspondientes al Partido Liberal Radical Auténtico en el gabinete, por tanto, no respondió a una lógica de apoyo parlamentario, es decir, de principio activo para ganar fuerza legislativa, sino a neutralizar una amenaza a su propia permanencia, amenaza que lo seguirá, seguramente, durante toda su gestión. 
El resto de los cargos de su gabinete se lo ofreció a dirigentes de los partidos pequeños integrantes de la Alianza Patriótica para el Cambio y a dos ex ministros colorados que presentan un perfil independiente. En ambos casos, el apoyo parlamentario conseguido como retribución es insignificante. Los ex ministros no tienen estructura y los grupos menores de la Alianza sólo consiguieron cinco escaños en ambas cámaras y están fuertemente enfrentados, envueltos en discusiones ideológicas y mutuas recriminaciones.

Cuadro 8: Distribución de bancas en el Senado

\begin{tabular}{llc}
\hline Partidos & Nombre & $\mathrm{N}^{\circ}$ bancas \\
\hline ANR & Asociación Nacional Republicana & 15 \\
PLRA & Partido Liberal Radical Auténtico & 14 \\
PPS & Partido País Solidario & 1 \\
UNACE & Unión Nacional de Ciudadanos Éticos & 9 \\
PPQ & Partido Patria Querida & 4 \\
PDP & Partido Democrático Progresista & 1 \\
MPT & Movimiento Popular Tekojoja & 1 \\
\hline
\end{tabular}

Fuente: Tribunal Superior de Justicia Electoral. “Elecciones 2008. Resultados Finales".

Cuadro 9: Conformación del Gabinete

\begin{tabular}{|c|c|c|}
\hline Ministerio & Ministro & Pertenencia Partidaria \\
\hline $\begin{array}{l}\text { Ministerio Secretario General y } \\
\text { Jefatura del Gabinete Civil }\end{array}$ & Miguel Ángel López Perito & Movimiento Popular Tekojoja \\
\hline $\begin{array}{l}\text { Ministerio de Agricultura y } \\
\text { Ganadería }\end{array}$ & Cándido Vera Bejarano & PLRA \\
\hline $\begin{array}{l}\text { Ministerio de la Defensa } \\
\text { Nacional }\end{array}$ & Luis Bareiro Spaini & $\begin{array}{l}\text { Ex militar sin adscripción } \\
\text { partidaria }\end{array}$ \\
\hline $\begin{array}{l}\text { Ministerio de Educación y } \\
\text { Cultura }\end{array}$ & Horacio Galeano Perrone & $\begin{array}{l}\text { Ex ministro del gobierno } \\
\text { colorado, que presentó su propio } \\
\text { grupo en las últimas elecciones, } \\
\text { sin obtener representación }\end{array}$ \\
\hline Ministerio de Hacienda & Dionisio Borda & $\begin{array}{l}\text { Ex ministro del gobierno } \\
\text { colorado, independiente }\end{array}$ \\
\hline $\begin{array}{l}\text { Ministerio de Industria y } \\
\text { Comercio }\end{array}$ & Martín Heisecke & $\begin{array}{l}\text { Empresario sin adscripción } \\
\text { partidaria, se lo menciona como } \\
\text { un importante financista de la } \\
\text { campaña de Lugo }\end{array}$ \\
\hline Ministerio del Interior & Rafael Filizzola & $\begin{array}{l}\text { Ex diputado por el Partido País } \\
\text { Solidario, presentó su propio } \\
\text { grupo en las últimas elecciones, } \\
\text { y obtuvo una banca en el Senado } \\
\text { y otra en diputados }\end{array}$ \\
\hline
\end{tabular}




\begin{tabular}{|c|c|c|}
\hline Ministerio & Ministro & Pertenencia Partidaria \\
\hline Ministerio de Justicia y Trabajo & Blas Llano & PLRA \\
\hline $\begin{array}{l}\text { Ministerio de Relaciones } \\
\text { Exteriores }\end{array}$ & Alejandro Hamed & $\begin{array}{l}\text { Embajador en el Líbano, contó } \\
\text { con el apoyo del PMAS, un } \\
\text { partido joven y combativo }\end{array}$ \\
\hline $\begin{array}{l}\text { Ministerio de Salud Pública y } \\
\text { Bienestar Social }\end{array}$ & Esperanza Martínez & Movimiento Popular Tekojoja \\
\hline $\begin{array}{l}\text { Ministerio de Obras Públicas y } \\
\text { Comunicaciones }\end{array}$ & Efraín Alegre & PLRA \\
\hline
\end{tabular}

Con los partidos más disciplinados en ambas cámaras, Partido Patria Querida y Unión Nacional de Ciudadanos Éticos, no se han establecido acuerdos, ni siquiera puntuales, de gobernabilidad. Por otro lado, si bien tampoco existieron manifestaciones claras de estos grupos respecto a la conformación de una alianza que desplace del gobierno al presidente y permita el ascenso de Federico Franco, los rumores no cesaron en todo el período.

Para resumir lo ocurrido, y de acuerdo a las insinuaciones públicas, en los primeros cien días de gobierno el péndulo de las mayorías parlamentarias estuvo más cerca de los dos tercios necesarios para habilitar el juicio político que de la mayoría simple requerida para llevar adelante las reformas prometidas, que no han obtenido todavía ningún apoyo desde el Legislativo.

\section{EL GOBIERNO DE LUGO EN EL CONTEXTO INTERNACIONAL}

La alternancia política luego de las elecciones de abril ha despertado interés en la región. Augusto Roa Bastos escribió alguna vez que Paraguay es una isla rodeada de tierra en el corazón del continente. Esto alude a una histórica exclusión que ocurre desde adentro, recordemos la pretensión autárquica de José Gaspar Rodríguez de Francia, el Supremo Dictador, y desde afuera, a partir del desconocimiento de una cultura peculiar y de una sucesión de conflictos bélicos entre los que se cuenta el infame antecedente de la Guerra de la Triple Alianza. Esta introspección tuvo una importante sacudida luego de conocidos los resultados electorales del 2008. Más allá de las cuestiones pintorescas que también hicieron al interés mediático, muchos atendieron a que Paraguay ingresaba en la región con un fuerte impulso democrático y progresista.

Sin embargo, todavía no está resuelto el lugar que asumirá el país en el concierto del Mercosur y América Latina. Para reubicarse requiere un importante nivel de capacidad de decisión al nivel interno, un mínimo consenso sobre la orientación general de la política exterior, que el gobierno está lejos de tener, y en el caso específico de las relaciones internacionales, con el desafío de lograr una renegociación del tratado de Itaipú o, en todo caso, de la obtención de algunos beneficios que permitan responder a las expectativas ciudadanas. Esto es un objetivo muy difícil, que lo lleva a debatir con el gobierno más poderoso, técnica y políticamente, de la región, desgastándose en 
una aventura con final incierto. Además, ni siquiera este frente de reforma, que podría tener un amplio consenso del sistema político, pudo congregar el suficiente apoyo que permita plantear el proyecto como una política de Estado.

Por el otro lado, y pensando en el alineamiento del país al "socialismo del siglo XX" las relaciones con Venezuela están sometidas a un escrutinio implacable de la prensa y los partidos de la oposición. En una sociedad conservadora sacar fantasmas para promover el miedo brinda buenos réditos políticos. La figura de Chávez como el demonio imperialista del sur aparece frecuentemente en editoriales y réplicas parlamentarias, marcando estrechos límites al presidente respecto a las posibilidades de alcanzar acuerdos de cooperación, ya no sólo con Venezuela sino con Bolivia y Ecuador.

El gobierno de Duarte Frutos y sus predecesores han tenido una estrecha relación con Taiwán. Su gobierno retribuía con una cooperación particularista la anual solicitud del presidente paraguayo de turno en la Asamblea General de las Naciones Unidas para que ese país ingrese en la organización. Esta ayuda, no sujeta a contraloría, que favorecía especialmente al presidente, parlamentarios, funcionarios del Ejecutivo y periodistas tuvo una fuerte y seguramente definitiva disminución cuando el Presidente Lugo no incluyó el pedido de reconocimiento a Taiwán dentro de su discurso en la Asamblea General. Este acto tuvo muy poca repercusión pública, a pesar de su importancia, y muestra cómo muchas veces la desarticulación de intereses creados tiene impactos negativos para el gobierno, sin que pueda recibir las gratificaciones correspondientes, como también muestra que el gobierno tiene poca capacidad de maniobra a nivel internacional, y su real inserción requiere, como todo el programa de reformas, de un marco de gobernabilidad efectivo.

\section{CONCLUSIONES}

A modo de balance, podemos afirmar que, sin dudas, Paraguay ha vivido un año histórico, en el que dio un gran paso hacia la consolidación democrática, habilitando una alternancia pacífica que honra a vencedores y vencidos. Ahora el ciudadano comienza a sentir el poder del voto, ya no existe un partido que se asume como el todo y que está más allá de las preferencias ciudadanas. Los votantes hicieron un juicio retrospectivo y tomaron una decisión que fue escuchada y respetada. En el futuro lo harán de nuevo, y de eso son conscientes también los gobernantes.

Sin embargo, la imposibilidad de construir un marco de gobernabilidad estable en el contexto de muy baja capacidad estatal inhibe la posibilidad de llevar adelante reformas estructurales que impliquen una redistribución de la riqueza, como la reforma agraria o una reforma fiscal. En distribución de tierras e ingresos Paraguay muestra niveles altísimos de inequidad, y ese desafío de cambio social que estaba en la base de la propuesta de Lugo no se pudo abordar eficazmente. La intención de aumentar la presión fiscal, por ejemplo, no resistió siquiera las primeras insinuaciones. La crisis financiera mundial resultó una buena excusa para eludir con elegancia el problema, y el gobierno rápidamente planteó su postergación indefinida. 
La voluntad no alcanza, y aún queda por ver, como desafío de los siguientes años, si el cambio de partido llevará finalmente a un cambio estructural para enfrentar los problemas sociales, lo que resulta difícil, o si el Ejecutivo sólo buscará alcanzar metas cercanas que le permitan navegar tiempos de bloqueos y desencuentros buscando capitalizar en el largo plazo un proceso de acumulación de poder que vaya más allá del obtenido en su histórico triunfo electoral.

Pero aquí surge la variable del tiempo. Quizás por la inestabilidad característica del sistema político o por las raíces de la cultura guaraní, los escenarios de acción de los distintos actores están regidos por el corto plazo. Los grupos sociales que no vean cumplidas sus expectativas, como también los liberales de la fracción del vicepresidente y los colorados desplazados tras décadas, buscarán cambios en la estructura de poder político que no necesariamente contemplan el respeto del período de cinco años de gobierno. Esto dificulta el establecimiento de procesos de cooperación y exige que el gobierno gestione los problemas inmediatos para asegurar una sobrevivencia que está en riesgo. Por tanto, el año 2009 mantendrá las características de una transición, con pocas posibilidades de alcanzar acuerdos y -es altamente probable-con un aumento de los conflictos. La duda es si la estrategia defensiva dejará espacios de maniobra para iniciar siquiera alguna de las reformas planteadas en un año electoral que promovió muchas expectativas en la ciudadanía...

\section{REFERENCIAS}

Banco Central del Paraguay. "Informe Económico". Asunción. Varios años.

Diario Última Hora. Asunción. Varios años.

Dirección General de Estadística, Encuestas y Censos. "Encuesta Permanente de Hogares". Asunción. Varios años.

Molina, José y Janeth Hernández. "La credibilidad de las elecciones latinoamericanas y sus factores. El efecto de los organismos electorales, el sistema de partidos y las actitudes políticas". Ponencia presentada en el XXI Congreso Internacional de la Asociación de Estudios Latinoamericanos (Latin American Studies Association, LASA). Chicago, Illinois. 24 al 26 de septiembre de 1998.

Programa Conjunto PNUD-UNICEF-UNFPA "Invertir en la Gente". "Impacto del aumento de precios de alimentos y de la crisis financiera global en la pobreza extrema" (paper). Asunción. Enero de 2009.

Programa de las Naciones Unidas para el Desarrollo en Paraguay. "Encuesta sobre indicadores de gobernabilidad". PNUD. 2009. Disponible en: http://www.undp.org.py/images_not/indicadores.zip

Rivarola, Milda. "Los repetidos y previsibles resultados". Revista Acción, n⿳ 233. Asunción. Mayo de 2003.

Tribunal Superior de Justicia Electoral. “Elecciones 2008. Resultados Finales”. Mayo de 2008.

Vial, Alejandro. “Cultura política y gobernabilidad democrática 2006”. CIRD. Asunción. 2006.

Vial, Alejandro. "Cultura política y prácticas de gobernabilidad democrática. La ciudadanía en su encrucijada". USAID, CIRD. Asunción. Noviembre de 2002.

Pablo Brugnoni es Politólogo de la Universidad de la República de Uruguay.

[E-mail: pablo.brugnoni@undp.org] 